\title{
Hypoxic episode during the larval period has long-term effects on European sea bass juveniles (Dicentrarchus labrax)
}

\author{
Vanderplancke Gwenaëlle ${ }^{1}$, Claireaux Guy ${ }^{1,2}$, Quazuguel Patrick ${ }^{1}$, Madec Lauriane ${ }^{1}$, Ferraresso \\ Serena $^{3}$, Sévère Armelle ${ }^{1}$, Zambonino-Infante Jose-Luis ${ }^{1}$, Mazurais David ${ }^{1}{ }^{*}$
}

${ }^{1}$ IFREMER, Ctr Brest, LEMAR UMR CNRS UBO IRD 6539, ZI La Pointe Du Diable,CS 10070, F-29280 Plouzane, France.

2 IFREMER, UBO, LEMAR UMR CNRS UBO IRD 6539, ZI La Pointe Du Diable, F-29280 Plouzane, France.

${ }^{3}$ Univ Padua, Dept Comparat Biomed \& Food Sci, I-35020 Legnaro, Italy.

* Corresponding author : David Mazurais, email address : david.mazurais@ifremer.fr

\begin{abstract}
:
Hypoxia episodes have been generally studied over the last decade for their lethal consequences in coastal areas, which are nurseries for several fish species. The possible long-lasting effects of nonlethal hypoxia exposures at larval stage are, however, poorly documented. We investigated the longlasting phenotypic impact of an experimental exposure to moderate hypoxia (40\% air saturation) between 30 and 38 days post-hatching in European sea bass (Dicentrarchus labrax). At the juvenile stage, our data indicate that this early hypoxia exposure impacted on juvenile growth rate but not on hypoxia tolerance. Growth depression was associated with a regulation of metabolism as suggested by a decrease in blood glycaemia, a decreased hepatic expression of the glucose transporter glut2 and of acaca involved in fatty acid synthesis as well as an increased hepatic expression of glycolytic $I d h-a$, which is a target gene of hypoxia inducible factors (HIFs). Interestingly, while fish were not exposed to hypoxia, the cellular oxygen sensor egln3 gene, which is also a target of HIFs, exhibited higher expression level in the hepatic tissue of juveniles that have experienced hypoxia at larval stage. Even if further studies are needed to evaluate the functional significance of such effects and to decipher the underlying molecular mechanisms, the present data evidence that early life exposure to a hypoxia event has long-lasting impact on sea bass juvenile physiology.
\end{abstract}


List of abbreviations used:

$\begin{array}{ll}\text { acaca } & \text { Acetyl-CoA Carboxylase Alpha } \\ \text { C } & \text { Control group } \\ \text { Ct } & \text { Cycle threshold } \\ \text { dph } & \text { Days Post Hatching } \\ \text { E } & \text { Primer Efficiency } \\ \text { ef1 } \alpha & \text { Elongation Factor-1, isoform alpha } \\ \text { Egln3 } & \text { Egg-Laying defective Nine 3 } \\ \text { ELHT } & \text { Early Life Hypoxia Treatment group } \\ \text { glut2 } & \text { Glucose transporter 2 } \\ \text { HCT } & \text { Hypoxic Challenge Test } \\ \text { HIF } & \text { Hypoxia Inducible Factor } \\ \text { igf-1 } & \text { Insulin-like growth factor-1 } \\ \text { Ldh-a } & \text { Lactate dehydrogenase-a } \\ \text { NI } & \text { Not Investigated } \\ \text { pH } & \text { power of Hydrogen } \\ \text { PIT } & \text { Passive Integrated Transponder } \\ \text { qPCR } & \text { Quantitative Polymerase Chain Reaction } \\ \text { RT } & \text { Reverse Transcription } \\ \text { s.d. } & \text { Standard Deviation }\end{array}$




\section{Introduction}

Over the past 50 years, global warming and anthropogenic activities have greatly influenced coastal marine ecosystems with profound and diverse consequences on water temperature, $\mathrm{pH}$ and dissolved oxygen. The occurrence of low dissolved oxygen (hypoxia) events in the world's coastal waters is becoming a major problem under the combined effects of expanding coastal eutrophication and global warming (Diaz and Rosenberg 1995; Diaz 2001). These hypoxic events are particularly severe in shallow coastal areas, compromising the survival, growth and recruitment of the young fish species that use these areas as nursery (Pihl et al. 1991; Breitburg 1992; Pihl et al. 1992). Hypoxic events have been shown to affect a broad range of physiological, developmental and behavioural processes with consequences thereof particularly in terms of growth and survival (Engstrom-Ost and Isaksson 2006; Ishibashi et al. 2007; McKenzie et al. 2008; Geist et al. 2013; Johnston et al. 2013; Yamanaka et al. 2013). These effects vary widely depending on fish species, hypoxia severity and duration, exposure period and individual acclimation capacities. Nevertheless, a common feature of hypoxia tolerance is the ability to regulate metabolism according to oxygen availability (Ishibashi et al. 2007; McKenzie et al. 2008). The physiological regulation underlying the phenotypic plasticity required to survive in adverse or unpredictable conditions during larval ontogeny could also result in long-lasting effects on animal performance and fitness at the adult stage (Desai and Hales 1997; Lindström 1999; Thompson 1999; Johnston and Temple 2002; Hamdoun and Epel 2007; Monaghan 2008). Marine fish species that exhibit a rapid rate of growth and development at larval stage may be particularly prone to such long-term effects. Long-term impact on fitness has been shown in fish following thermal variation in the larval environment (Johnston et al. 1996; Zambonino-Infante et al. 2013). However, until now, the long-term consequences of plasticity that allows fish larvae to meet the challenges of a temporarily hypoxic environment are unknown.

It is well documented in vertebrates, including fish, that preconditioning adult tissues to low oxygen availability improves subsequent tolerance to hypoxia and ischemia (Mulvey and Renshaw 2000; Kohin et al. 2001; Lu et al. 2005; Cook et al. 2013). Energy-saving combined with hypometabolism are thought to be involved in the development of such preconditioninginduced hypoxic tolerance (Mulvey and Renshaw 2000; Lu et al. 2005). It is accepted that Hypoxia Inducible Factors (HIFs), which transduce reduced oxygen availability into adaptive cellular responses based on the regulation of gene expression, contribute to the protective 
effects of ischemic preconditioning (for review see Semenza (2011)). A beneficial transgenerational effect of parental hypoxic exposure on hypoxia tolerance of offspring has been demonstrated in zebrafish (Danio rerio) indicating epigenetic mechanisms underlying these effects (Ho and Burggren 2012). Even if epigenetic modulation can occur throughout life, it is now admitted that the early life stage of organisms is highly susceptible to such regulation since it is a period of rapid cell division and epigenetic remodelling (Perera and Herbstman, 2011). The resulting developmental plasticity allows the organism to make anticipatory responses to the external environment by altering the course of cellular and organ differentiation.

In the European sea bass, spawning takes place off shore and larvae drift to coastal nurseries that they will reach at approximately flexion stage (Dufour et al., 2009; Jennings and Pawson, 1992). From that stage until they become sufficiently mobile, young sea bass will be exposed to the environmental fluctuations that characterize coastal ecosystems, including hypoxic events.

In the present study, we hypothesized that a moderate hypoxic episode (40\% air saturation) occurring at ecological relevant windows of larval development could have long-lasting effects on the physiological performance of the resulting juveniles. Growth rate as well as tolerance to a standardized hypoxic challenge (Roze et al., 2013) was used to evaluate the global physiological status of juveniles. Considering that hypoxia is known to influence the energy metabolism through HIF signalling cascade, we wondered if early exposure to hypoxia could also have abiding effects on molecular actors involved in these pathways. In order to test this hypothesis, some molecular and biochemical parameters related to metabolism and HIF pathway have been addressed. 


\section{Material and methods}

\section{(a) Animals}

\section{Phase 1: Larval rearing and treatments}

One day post hatching (dph) larvae of European sea bass were purchased from a commercial hatchery (Aquastream, Ploemeur, France). They were distributed among 8 tanks supplied with open flow and aerated sea water (temperature: $19.1 \pm 0.4^{\circ} \mathrm{C}$; salinity: $35 \pm 0.2$ ). Larvae were fed with Artemia until the end of larval development according to Zambonino-Infante et al. (1996). From 30 to $38 \mathrm{dph}$, water oxygenation in 4 of the tanks (early life hypoxia treatment, labelled ELHT) was reduced to approximately $40 \%$ while it was maintained at full saturation in the other 4 tanks (normoxic treatment, labelled $\mathrm{N}$ ). Hypoxia was generated by bubbling $\mathrm{N}_{2}$ in a gas equilibration column placed upstream from the experimental tank. Dissolved $\mathrm{O}_{2}$ was monitored daily using an Odeon oxygen meter (ODEON Classic OPTOD, Caudan, France). The water quality parameters (salinity, temperature, $\mathrm{pH}$ ) were also daily checked in each tank during the experiment. The level of hypoxia was established on the basis of a preliminary study which showed that below $40 \%$ air saturation the survival of $30 \mathrm{dph}$ sea bass larvae is significantly reduced. At the end of hypoxia-exposure, i.e. at $38 \mathrm{dph}$, larvae were returned to normal oxygen condition until $45 \mathrm{dph}$ (end of phase 1). Survival rates were evaluated for each experimental group at the end of larval development (i.e. $45 \mathrm{dph}$ ).

\section{Sampling}

At 38 dph i.e., just before returning hypoxic groups to normal oxygenation conditions, 12 pools of 3 larvae were sampled from each tank, euthanized with an excess of anaesthetic and processed for RNA extractions. Seven days later (45 dph), 50 larvae from each tank were euthanized with excess of anaesthetic and individually weighed.

\section{Phase 2 : Juvenile rearing treatments}

Intermediate growing phase

At 50dph, replicate tanks were pooled in one, $1 \mathrm{~m}^{3}$-tank per treatment (normoxia; $19.1 \pm$ $0.4^{\circ} \mathrm{C}$ ). Fish were then fed with a commercial diet (NeoSupra, Coopérative Le Gouessant, Lamballe, Côtes-d'Armor, France). At 119 dph, 40 fish from the ELHT and C tanks were selected to represent the frequency distribution of mass in their tank of origin i.e. C: $4.7 \pm 1.7$ g; H $4.7 \pm 2.1$ g. They were tagged subcutaneously (Passive Integrated Transponder; PIT-tag) for individual identification and pooled in the same $2 \mathrm{~m}^{3}$-tank. Fish were fed with NeoGrower 
commercial diet (Coopérative Le Gouessant, Lamballe, Côtes-d'Armor, France) and maintained at $24^{\circ} \mathrm{C}$. From day 344 to day 358, fish were fed by hand three times a day to visual satiety (visual observation of first feed refusal) over 30 -min periods. The quantity of feed distributed per day was recorded, normalized to the biomass in each group and corresponded to the normalized food ingestion rate (NFIR, expressed in percentage). Physiological performance (growth rate and hypoxia tolerance), biochemical (glycaemia) and molecular (gene expressions) evaluations of fish were performed between 295 to $365 \mathrm{dph}$.

\section{Hypoxia Challenge Test (HCT)}

At $253 \mathrm{dph}$, feeding was discontinued for $48 \mathrm{~h}$ before a standardized hypoxia challenge test was conducted in the rearing tanks according the protocol described in Roze et al (2013). Briefly, water oxygenation was initially decreased from $100 \%$ air saturation (air sat) down to $10 \%$ air sat within one hour, followed by a slower descent at $1.2 \%$ air sat per hour until the experiment ended (approximately $4 \%$ air sat). Ambient oxygenation was controlled by bubbling nitrogen in the intake of a submersible pump placed in the tank. Dissolved $\mathrm{O}_{2}$ was continuously monitored using two oxygen meters distributed in the tank (ODEON Classic OPTOD, Caudan, France). The hypoxia challenge test (HCT) consisted in identifying fish (PIT tag reading) as they lost their capacity to maintain their equilibrium. Upon idendification, fish were quickly placed in a fully aerated tank for recovery. The corresponding time and oxygenation level were recorded. The HCT ended when the last fish was recovered.

\section{Growth monitoring}

Fish from each group were weighed at 295, 309, 329, 343 and 361 dph after light anaesthesia (phenoxyethanol: 200 ppm).

\section{Blood and tissue samples}

At $365 \mathrm{dph}, 48 \mathrm{~h}$ prior to sampling, individuals were left undisturbed and unfed. Fifteen fish from each group were anesthetized (phenoxyethanol, $200 \mathrm{ppm}$ ) and a 1-mL blood was drawn from their caudal vein using a heparinized syringe. The fish were then euthanized with an excess of anaesthetic, their livers excised and a piece of white muscle dissected from the dorsal region. Samples were weighed and quickly placed in liquid nitrogen. Fish from both groups were sampled alternately. Since, time of day is believed to influence blood parameters e.g., glycaemia, as well as gene expression, sampling time was used as cofactor in the statistical analyses. Tissue samples were kept at $-80^{\circ} \mathrm{C}$ until analyses. 
All experiments were conducted in strict compliance with the Guide for the Care and Use of Laboratory Animals.

\section{(b) Analytical methods}

\section{Glycaemia}

Blood samples were centrifuged at $10,000 \mathrm{~g}$ for $8 \mathrm{~min}$ at $4^{\circ} \mathrm{C}$ and the plasma was carefully collected, aliquoted and stored at $-20^{\circ} \mathrm{C}$. Glycaemia was assessed using glucose RTUTM kit (bioMérieux; Marcy l'Etoile, Rhône, France) according to the manufacturer's instructions.

\section{Gene expression analysis}

\section{Preparation of total RNA}

Samples (50 to $100 \mathrm{mg}$ ) were placed in $1 \mathrm{~mL}$ of Extract-all reagent (Eurobio; Courtaboeuf, Essone, France) and homogenised using a Pro Polytron ${ }^{\circledR}$ (BioBlock Scientific; Illkirch, BasRhin, France) tissue disruptor for $30 \mathrm{~s}$. Total RNA was extracted following the manufacturer's instructions. Potential contaminating DNA was removed using an RTS DNase $^{\text {TM }}$ Kit (MoBio Laboratories Inc.; Carlsbad, CA, USA) according to manufacturer's recommendations. The quantity and purity of RNA were assessed using a ND-1000 NanoDrop ${ }^{\circledR}$ spectrophotometer (Thermo Scientific Inc.; Waltham, MA, USA). The integrity of RNA was determined by electrophoresis using an Agilent Bioanalyser 2100 (Agilent Technologies Inc.; Santa Clara, CA, USA). RNA samples were stored at $-80^{\circ} \mathrm{C}$ until use.

\section{cDNA synthesis}

After extraction, total RNA was reverse transcribed into cDNA using an iScript ${ }^{\mathrm{TM}} \mathrm{cDNA}$ Synthesis kit (Bio-Rad Laboratories Inc.; Hercules, CA, USA) following the manufacturer's instructions. Briefly, $1 \mu \mathrm{g}$ total RNA was reverse transcribed into cDNA in a volume of 20 $\mu \mathrm{L}$, composed of $15 \mu \mathrm{L}$ of sample, $4 \mu \mathrm{L} 5 \mathrm{x}$ iScript ${ }^{\mathrm{TM}}$ Reaction Mix, containing oligo(dT), random primers and RNaseA inhibitor, and $1 \mu \mathrm{L}$ of iScript ${ }^{\mathrm{TM}}$ Reverse transcriptase. Reverse transcription (RT) was performed using a Thermo-cycler TC-152 (Techne Barloworld Scientific; Stone, Staffordshire, UK). cDNA was stored at $-20^{\circ} \mathrm{C}$ until use. RT negative controls (no reverse transcriptase) were performed on each sample.

\section{Real time PCR (qPCR)}

Prior to analysis, PCR efficiency was estimated for each primer pair using serial dilutions (from $1 / 5$ to $1 / 320$ ) of a pool of cDNA. Primer efficiency (E) was determined using the slope 
of the standard curves obtained by the formula $E=10^{\frac{-1}{\text { slope }}}$. Through this analysis we ensured that PCR efficiencies ranged from $95 \%$ to $105 \%$ for each primer pair. Primers were designed using Primer3 software v.0.4. (http://bioinfo.ut.ee/primer3-0.4.0/), based on sequences available from ncbi (www.ncbi.nlm.nih.gov), the sigenae website (http://www.sigenae.org/) or a specific sea bass database developed by Ferraresso et al. (2010) (http://enne.cribi.unipd.it:5556/biomart/martview/) (Table 1).

For each sample, qPCR were performed in triplicate using $\mathrm{iQ}^{\mathrm{TM}} \mathrm{SYBR}{ }^{\circledR}$ Green Supermix (Bio-Rad Laboratories Inc.; Hercules, CA, USA), following the manufacturer's instructions. Briefly, qPCR amplifications were carried out in a final well volume of $15 \mu \mathrm{L}$ containing 5 $\mu \mathrm{L}$ cDNA (1/20 dilution) and $10 \mu \mathrm{L}$ reaction mix, composed of $7.5 \mu \mathrm{L}$ iQ ${ }^{\mathrm{TM}} \mathrm{SYBR}{ }^{\circledR}$ Green Supermix, containing antibody-mediated hot-started iTaq DNA polymerase, dNTPs, $\mathrm{MgCl} 2$, SYBR ${ }^{\circledR}$ Green I dye, enhancers, stabilizers and fluorescein; $1.5 \mu \mathrm{L}$ RNase/DNase free water and $0.5 \mu \mathrm{L}$ of each primer $(10 \mathrm{mM})$. Runs started with a 3 min activation of the hot-started iTaq DNA polymerase at $95^{\circ} \mathrm{C}$. Then, $45 \mathrm{PCR}$ amplification cycles, consisting of $30 \mathrm{~s}$ at $95^{\circ} \mathrm{C}$ and $1 \mathrm{~min}$ at $60^{\circ} \mathrm{C}$, were performed for all primer pair sets, using an automated iCycler MyiQ $^{\mathrm{TM}}$ Single Color Real-Time PCR Detection System (Bio-Rad Laboratories Inc.; Hercules, CA, USA). In order to evaluate the quality of amplification, melt curve analyses were performed at the end of the PCR protocol. RT negative controls were used as template in order to ensure the absence of residual DNA contamination.

\section{Relative quantification}

For each sample, the corresponding $\mathrm{Ct}$ (Cycle threshold) value was determined automatically using Bio-Rad iQ5 software. The relative quantity of messenger was normalised and measured by Bio-Rad iQ5 software using the $\Delta \Delta \mathrm{Ct}$ method. The elongation factor 1-alpha (efla) gene was chosen as housekeeping gene since its mRNA levels did not exhibit any significant variation between samples (relative standard deviation $<5 \%$ ) or between the two experimental groups (one-way ANOVA: $\mathrm{p}>0.5$ ). Efl $\alpha$ gene was already used as reference gene in previous study related to the investigation of target genes expression during hypoxia exposure of fish (e.g. Olsvik et al., 2013).

\section{(c) Statistical analyses}

Statistical analyses were performed using R software (R Core Team 2013). For all analyses, variables were checked for normality (Shapiro test) and equality of variances (Levene test). Linear regression was performed to analyse survival rates at the end of larval development. 
Larval mass at $45 \mathrm{dph}$ were compared using Student-test. One way ANOVA (ELHT versus C) was used for larvae gene expression analyses. ANCOVA have been applied on glycaemia and juvenile gene expression analyses using sampling time as a cofactor and early life oxygenation conditions as the main effect. To analyse potential impact of early oxygenation conditions on growth, a repeated measure mixed model approach was conducted where five time points $(295,309,329,343$ and $361 \mathrm{dph})$ were repeated measures of mass for each fish. Finally, a Mantel-Cox model (also called logRank test) was used for the hypoxic challenge analysis, with early life oxygen treatment as main effect. Differences were considered significant at the $95 \%$ confidence level $(p-v a l u e<0.05)$.

\section{Results}

\section{Effect of hypoxia exposure during the larval stage}

Growth $(\mathrm{C}=38.9 \pm 12.5 \mathrm{mg}$; ELHT $=34.7 \pm 12.9 \mathrm{mg} ; \mathrm{p}>0.09)$ and survival rate $(\mathrm{C}=44.9 \pm$ $7.2 \% ; \mathrm{ELHT}=44.7 \pm 5.3 \% ; \mathrm{p}=1)$ were similar in the $\mathrm{C}$ and ELHT groups at the end of larval

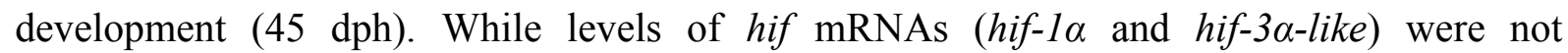
significantly influenced by hypoxia, the amount of egln 3 transcripts was significantly higher (400\%) in larvae that had been exposed to low ambient oxygenation (Table 2). Concerning genes involved in metabolism, the quantities of $l d h-a$ and glut 2 transcripts were significantly higher $(21.3 \%$ and $46 \%$, respectively) in the hypoxic environment contrary to acaca, which exhibited lower mRNA levels (11\%).

\section{Effect of larval hypoxia exposure on juvenile growth}

Growth of juveniles was monitored from 295 dph, i.e. 257 days after the hypoxia exposure ended (Fig. 1). Juvenile growth rate was significantly affected by early life oxygen treatment (repeated measures mixed model: $\mathrm{p}<0.05$ ) with a 5\% lower growth rate in the ELHT group compared to the $\mathrm{C}$ group. No significant difference in feed intake was observed between the two groups $\left(\mathrm{NFIR}_{\mathrm{C}}=1.6 \pm 0.001 \% ; \mathrm{NFIR}_{\mathrm{ELHT}}=1.6 \pm 0.001 \%\right)$.

\section{Effect of larval hypoxia exposure on glycaemia in juveniles}


Blood glycaemia was assessed in juveniles from both two groups at $365 \mathrm{dph}$. Glycaemia was significantly higher in juveniles from the ELHT group $(+16 \%)$ than from the $\mathrm{C}$ group $(\mathrm{C}=8$ \pm 1.2 mmoles. L $^{-1}$, ELHT $=6.7 \pm 0.8$ mmoles. $\mathrm{L}^{-1}$; ANCOVA: $\left.\mathrm{p}<0.001\right)$.

\section{Effect of larval hypoxia exposure on the expression of genes involved in metabolism, oxygen sensing and growth in juveniles}

Real time PCR analysis (Table 2) showed significant increase of liver ldh-a expression (23.9 $\%$ ) in juveniles from ELHT group. The glucose transporter glut2 exhibited also significant decreased (12.3\%) expression in the liver of ELHT group. By contrast, there was no significant difference in the transcript levels of $l d h-a$ and glut2 genes in the white muscle between the two groups. Acaca gene exhibited lower mRNA levels $(23.3 \%)$ in the liver of juveniles from ELHT group compared with the C group. However, its expression was not significantly regulated in the white muscle tissue.

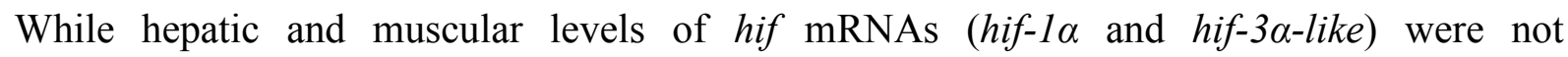
significantly impacted by early exposure to hypoxia, levels of egln 3 transcripts were significantly higher in the liver $(46.2 \%)$ but not in the skeletal muscle $(p=0.09)$ of the ELHT group compared with the $\mathrm{C}$ group.

Finally, qPCR investigation did not reveal any differential expression of the Insulin-like Growth Factor-1 (igf-1) gene in hepatic nor in muscular tissues.

\section{Effect of larval hypoxia exposure on juvenile tolerance to an acute hypoxia challenge}

Comparison of experimental groups with regard to hypoxia tolerance showed no statistically significant difference (Fig.2). Time to cull $50 \%$ of the population was $346.9 \mathrm{~min}$ in the C group and 349.9 minutes in the ELHT group; Mantel-Cox model: $\mathrm{p}>0.5$ ).

\section{Discussion}

The present work demonstrates that early life exposure to a moderate hypoxic event has longlasting effects on the phenotype of a marine fish species. It is noteworthy that compared to the normoxic group, the hypoxic constraint applied in the present study did not induce significant mortality. This strongly suggests that no selection occurred under low oxygenation towards specific physiological performance. Rearing conditions were chosen to be appropriate for harmonious larval and juvenile development. The efficient growth rates that we observed for 
both larval and juvenile periods are evidence of this suitability, which strengthens the validity of physiological data obtained.

Early exposure to moderate hypoxic conditions had a long-term impact on fish growth rate. There have been few reports, until now, of any delayed effect of hypoxia on growth. Work by Craig et al. (2007) and Eby et al. (2005) only addressed an indirect delayed effect of hypoxia exposure on the growth of fish fleeing from hypoxic areas to oxygenated but confined areas. Present data suggest that a delayed effect on growth rate following exposure of fish to low oxygen concentrations can also result from a direct impact of an early hypoxic stress on fish physiology. Immediate stunting induced by hypoxia has been observed in various fish species at different life stages [e.g. Atlantic menhaden (Brevoortia tyrannus) (McNatt and Rice 2004), red drum (Sciaenops ocellatus) (Perez-Dominguez and Holt 2006), summer flounder (Paralichthys dentatus), winter flounder (Pseudopleuronectes americanus) (Stierhoff et al. 2006), yellowfin tuna (Thunnus albacares) (Wexler et al. 2011) and great sturgeon (Huso huso) (Lakani et al. 2013)]. The short term impact on growth is known to be due to reduced feed intake and metabolic depression (Pichavant et al., 2000, Stierhoff et al. 2006). It is noteworthy that the hypoxic constraint experienced by the larvae between 30 and $38 \mathrm{dph}$ did not significantly affect their mass at the end of larval development (i.e. $45 \mathrm{dph}$ ). Since exposure to hypoxia was expected to induce immediate growth impairment due to reduced feed intake and metabolic depression, the similarity of the mean weight observed in both groups at $45 \mathrm{dph}$ may be explained by a compensatory growth occurring in larvae from the ELHT group between 38 and $45 \mathrm{dph}$. Feed intake of larvae was not monitored during exposure to hypoxia since it would have required radiolabeled nutrients (Conceição et al., 2007) but the respective up and down-regulation of $l d h-a$ and acaca genes observed at $38 \mathrm{dph}$ suggested a possible regulation of metabolic processes during larval exposure to hypoxia.

It has been suggested that compensatory strategies occurring during early life stages, even if they offer immediate benefits, involve functional trade-offs which may result in lower fitness at later life stage (Metcalfe and Monaghan 2001; Metcalfe and Monaghan 2003; Monaghan 2008, Burton et al., 2011). The long-term impact of hypoxia exposure on juvenile growth that we observed may result from just such a physiological trade-off. It is indeed noteworthy that the reduced growth observed in the ELHT group was not a consequence of lower feed intake and that is was not associated to modification in the expression of the growth-related gene igf1 .

The subsequent impacts on physiological performance of stressful conditions experienced during early development have been suggested to involve metabolic disorders (Metcalfe and 
Monaghan 2003, Burton et al., 2011). Even if present gene expression data should be taken with caution since they do not reflect the concentration and/or activity of the related proteins, the down-regulation of acaca gene and the up-regulation ldh-a gene in the hepatic tissue of juveniles support this idea. Such regulation suggests that juveniles that experienced low oxygen conditions at the larval stage are likely to exhibit a metabolism with specific features observed in organisms acutely exposed to hypoxia (Richards 2009) i.e. a tendency to activate the anaerobic metabolism and to limit the functioning of energy consuming (e.g. fatty acid synthesis) metabolic pathways in the liver. Additional biochemical analyses (e.g. activity of key enzymes of aerobic and anaerobic metabolic pathways such as LDH-a, citrate synthase or citrate oxidase) would be necessary to confirm a metabolic depression-related impaired growth in the juveniles that experienced low oxygen concentration during the larval stage. Moreover, the repeatability of our data related to metabolic parameters would deserve to be confirmed by multiple measurements.

The lower glycaemia and the down-expression of the glucose transporter glut 2 in the liver of juveniles from the ELHT group supports long lasting impact of hypoxia exposure on glucose metabolism. The lower glycaemia combined with the down-expression of glut 2 supports good correlation between glut2 expression in liver and blood glucose observed by Hall et al. (2006) in Atlantic cod (Gadus morhua). Since regulation of plasma glucose concentration results from a complex interplay between several tissues (muscle, liver, brain, fat, gut and others...), further investigation will be necessary to decipher the different pathways involved in the control of energy metabolism and particularly glucose metabolism. Present data reveal that glut2, acaca and ldh-a gene expressions were not significantly modulated in muscle suggesting that muscular metabolism of juveniles would be less sensitive to early hypoxia exposure.

Even if the molecular mechanisms underlying this plastic physiological response still need to be deciphered, results obtained in the present work suggest that the HIF pathway might be involved in the determination of this phenotype. Juveniles preconditioned to hypoxia during their larval stage exhibit a higher expression of the egln 3 gene in the hepatic tissue. $E g \ln 3$ is involved in the hydroxylation of HIF proteins and it is considered as a cellular oxygen sensor. It has been shown to be a privileged target gene of HIFs in mammals (Pescador et al. 2005). In addition, hepatic ldh-a expression and blood glucose concentration that we found regulated in juveniles preconditioned to hypoxia, are two biological parameters known to be influenced by HIF signalling (Firth et al. 1995; McClain et al. 2013). It is then reasonable to assume a regulation of HIF pathway in juveniles previously exposed to hypoxia, although we failed to 
detect any significant regulation of HIF gene at the transcriptional level. This hypothesis has to be confirmed in a near future by the investigation of post transcriptional regulation of HIFs (e.g. hydroxylation, acetylation).

One other interesting result of the present study is that similar regulations of egln 3 and $l d h-a$ genes were found in larvae under hypoxic conditions and in the liver of subsequent juveniles although maintained under normoxic conditions. This data suggests that transcriptional imprinting could have occurred during the early exposure to hypoxia. Although further investigations will be necessary to determine the molecular mechanisms underlying this regulation, we assume that an epigenetic modulation could be responsible for such hypoxiainduced transcriptional imprinting as already reported in fish (Ho and Burggren 2012).

No effect of hypoxia preconditioning on hypoxia tolerance was observed in the present work. This result is counterintuitive since preconditioning was also associated with changes in molecular components believed to be involved in the response to reduced oxygen availability. This is also contrasting with previous reports suggesting that hypoxia acclimation improved hypoxia tolerance in fish (Fu et al., 2011; Yang et al., 2013). However, our result was based on an acute hypoxic challenge and cannot predict responses of preconditioned juveniles to chronic hypoxic constraints.

\section{Conclusion}

Altogether the results of present study provide evidences that early exposure to moderate hypoxia impacts the subsequent fish growth and some metabolic parameters. This data is interesting since it could inform decisions aimed at anticipating the ecological and economical consequences of climate-related changes in production systems. From an animal production perspective, it could also provide an interesting tool for the aquaculture industry to capitalize on phenotypic plasticity, and not only genetic selection, to optimize production in a changing environment. 


\section{Acknowledgements}

The authors wish to thank Helen McCombie for her help with editing the English language.

The first author was supported by a joint Ifremer-Région Bretagne doctoral grant.

\section{Competing interests}

No competing interests declared. 


\section{Reference List}

Breitburg DL (1992) Episodic hypoxia in Chesapeake Bay : Interacting effects of recruitment, behavior, and physical disturbance. Ecol Monogr 62: 525-546 doi 10.2307/2937315

Burton T, Killen SS, Armstrong JD, Metcalfe NB (2011) What causes intraspecific variation in resting metabolic rate and what are its ecological consequences? Proc R Soc B 278: 3465-3473 doi 10.1098/rspb.2011.1778

Conceicao LEC, Morais S, Ronnestad I (2007) Tracers in fish larvae nutrition: A review of methods and applications. Aquaculture 267: 62-75 doi 10.1016/j.aquaculture.2007.02.035

Cook DG, Iftikar FI, Baker DW, Hickey AJR, Herbert NA (2013) Low-O-2 acclimation shifts the hypoxia avoidance behaviour of snapper (Pagrus auratus) with only subtle changes in aerobic and anaerobic function. J Exp Biol 216: 369-378 doi 10.1242/jeb.073023

Craig JK, Rice JA, Crowder LB, Nadeau DA (2007) Density-dependent growth and mortality in an estuary-dependent fish: an experimental approach with juvenile spot Leiostomus xanthurus. Mar Ecol-Prog Ser 343: 251-262 doi 10.3354/meps06864

Desai M, Hales CN (1997) Role of fetal and infant growth in programming metabolism in later life. Biol Rev 72: 329-348 doi 10.1017/s0006323196005026

Diaz RJ (2001) Overview of hypoxia around the world. J Env Qual 30: 275-281 doi $10.2134 /$ jeq2001.302275x

Diaz RJ, Rosenberg R (1995) Marine benthic hypoxia: A review of its ecological effects and the behavioural responses of benthic macrofauna. Oceanogr Mar Biol 33: 245-303

Dufour V, Cantou M, Lecomte F (2009) Identification of sea bass (Dicentrarchus labrax) nursery areas in the north-western Mediterranean Sea. JMBA 89: 1367-1374 doi $10.1017 / \mathrm{s} 0025315409000368$

Eby LA, Crowder LB, McClellan CM, Peterson CH, Powers MJ (2005) Habitat degradation from intermittent hypoxia: impacts on demersal fishes. Mar Ecol-Prog Ser 291: 249261 doi 10.3354/meps291249

Engstrom-Ost J, Isaksson I (2006) Effects of macroalgal exudates and oxygen deficiency on survival and behaviour of fish larvae. J Exp Mar Biol Ecol 335: 227-234 doi 10.1016/j.jembe.2006.03.007

Ferraresso S, Milan M, Pellizzari C, Vitulo N, Reinhardt R, Canario AVM, Patarnello T, Bargelloni L (2010) Development of an oligo DNA microarray for the European sea bass and its application to expression profiling of jaw deformity. Bmc Genomics 11: 17 doi 10.1186/1471-2164-11-354

Firth JD, Ebert BL, Ratcliffe PJ (1995) Hypoxic regulation of Lactate-Dehydrogenase-A. Interaction between Hypoxia-Inducible Factor-1 and cAMP response elements. J Biol Chem 270: 21021-21027

Fu SJ, Brauner CJ, Cao ZD, Richards JG, Peng JL, Dhillon R, Wang YX (2011) The effect of acclimation to hypoxia and sustained exercise on subsequent hypoxia tolerance and swimming performance in goldfish (Carassius auratus). J Exp Biol 214: 2080-2088 doi $10.1242 /$ jeb.053132

Geist SJ, Ekau W, Kunzmann A (2013) Energy demand of larval and juvenile Cape horse mackerels, Trachurus capensis, and indications of hypoxia tolerance as benefit in a changing environment. Mar Biol 160: 3221-3232 doi 10.1007/s00227-013-2309-2

Hall JR, Short CE, Driedzic WR (2006) Sequence of Atlantic cod (Gadus morhua) GLUT4, GLUT2 and GPDH: Developmental stage expression, tissue expression and relationship to starvation-induced changes in blood glucose. J Exp Biol 2006:4490502

Hamdoun A, Epel D (2007) Embryo stability and vulnerability in an always changing world. PNAS 104: 1745-1750 doi 10.1073/pnas.0610108104 
Ho DH, Burggren WW (2012) Parental hypoxic exposure confers offspring hypoxia resistance in zebrafish (Danio rerio). J Exp Biol 215: 4208-4216 doi 10.1242/jeb.074781

Ishibashi Y, Kotaki T, Yamada Y, Ohta H (2007) Ontogenic changes in tolerance to hypoxia and energy metabolism of larval and juvenile Japanese flounder Paralichthys olivaceus. J Exp Mar Biol Ecol 352: 42-49 doi 10.1016/j.jembe.2007.06.036

Jennings S, Pawson MG (1992) The origin and recruitment of bass, Dicentrarchus labrax, larvae to nursery areas. J Mar Biol Ass 72:199-212 doi 10.1017/S0025315400048888

Johnston EF, Alderman SL, Gillis TE (2013) Chronic Hypoxia Exposure of Trout Embryos Alters Swimming Performance and Cardiac Gene Expression in Larvae. PBZ 86: $567-$ 575 doi 10.1086/672012

Johnston I, Vieira V, Hill J (1996) Temperature and ontogeny in ectotherms: muscle phenotype in fish. Anim Temp: 153-181

Johnston IA, Temple GK (2002) Thermal plasticity of skeletal muscle phenotype in ectothermic vertebrates and its significance for locomotory behaviour. J Exp Biol 205: 2305-2322

Kohin S, Stary CM, Howlett RA, Hogan MC (2001) Preconditioning improves function and recovery of single muscle fibers during severe hypoxia and reoxygenation. Am J Physiol-Cell Physiol 281: C142-C146

Lakani FB, Sattari M, Falahatkar B (2013) Effect of different oxygen levels on growth performance, stress response and oxygen consumption in two weight groups of great sturgeon Huso huso. Iran J Fish Sci 12: 533-549

Lindström J (1999) Early development and fitness in birds and mammals. Trends Ecol Evol 14: 343-348 doi 10.1016/s0169-5347(99)01639-0

Lu GW, Yu S, Li RH, Cui XY, Gao CY (2005) Hypoxic preconditioning - A novel intrinsic cytoprotective strategy. Mol Neurobiol 31: 255-271 doi 10.1385/mn:31:1-3:255

McClain DA, Abuelgasim KA, Nouraie M, Salomon-Andonie J, Niu XM, Miasnikova G, Polyakova LA, Sergueeva A, Okhotin DJ, Cherqaoui R, Okhotin D, Cox JE, Swierczek S, Song J, Simon MC, Huang JY, Simcox JA, Yoon D, Prchal JT, Gordeuk VR (2013) Decreased serum glucose and glycosylated hemoglobin levels in patients with Chuvash polycythemia: a role for HIF in glucose metabolism. J Mol Med-Jmm 91: 59-67 doi 10.1007/s00109-012-0961-5

McKenzie DJ, Lund I, Pedersen PB (2008) Essential fatty acids influence metabolic rate and tolerance of hypoxia in Dover sole (Solea solea) larvae and juveniles. Mar Biol 154: 1041-1051 doi 10.1007/s00227-008-0998-8

McNatt RA, Rice JA (2004) Hypoxia-induced growth rate reduction in two juvenile estuarydependent fishes. J Exp Mar Biol Ecol 311: 147-156 doi 10.1016/j.jembe.2004.05.006

Metcalfe NB, Monaghan P (2001) Compensation for a bad start: grow now, pay later? Trends Ecol Evol 16: 254-260 doi 10.1016/s0169-5347(01)02124-3

Metcalfe NB, Monaghan P (2003) Growth versus lifespan: perspectives from evolutionary ecology. Exp Gerontol 38: 935-940 doi 10.1016/s0531-5565(03)00159-1

Monaghan P (2008) Early growth conditions, phenotypic development and environmental change. Phil Trans B 363: 1635-1645 doi 10.1098/rstb.2007.0011

Mulvey JM, Renshaw GMC (2000) Neuronal oxidative hypometabolism in the brainstem of the epaulette shark (Hemiscyllium ocellatum) in response to hypoxic pre-conditioning. Neurosci Lett 290: 1-4 doi 10.1016/s0304-3940(00)01321-5

Olsvik PA, Vikesa V, Lie KK, Hevroy EM (2013) Transcriptional responses to temperature and low oxygen stress in Atlantic salmon studied with next-generation sequencing technology. Bmc Genomics 14: 817. doi: 10.1186/1471-2164-14-817 
Perera F, Herbstman J (2011) Prenatal environmental exposures, epigenetics, and disease. Reprod Toxicol 31:363-373 doi: 10.1016/j.reprotox.2010.12.055.

Perez-Dominguez R, Holt GJ (2006) Interrenal and thyroid development in red drum (Sciaenops ocellatus): Effects of nursery environment on larval growth and cortisol concentration during settlement. Gen Comp Endocr 146: 108-118 doi 10.1016/j.ygcen.2005.10.006

Pescador N, Cuevas Y, Naranjo S, Alcaide M, Villar D, Landazuri M, Del Peso L (2005) Identification of a functional hypoxia-responsive element that regulates the expression of the egl nine homologue 3 (egln3/phd3) gene. Biochem J 390: 189-197 doi $10.1042 /$ bj20042121

Pichavant K, Person-Le-Ruyet J, Le Bayon N, Sévère A, Le Roux A, Quéméner L, Maxime V, Nonnotte G, Bœuf G (2000). Effects of hypoxia on growth and metabolism of juvenile turbot. Aquaculture 188:103-114

Pihl L, Baden SP, Diaz RJ (1991) Effects of periodic hypoxia on distribution of demersal fish and crustaceans. Mar Biol 108: 349-360 doi 10.1007/bf01313644

Pihl L, Baden SP, Diaz RJ, Schaffner LC (1992) Hypoxia-induced structural changes in the diet of bottom-feeding fish and crustacea. Mar Biol 112: 349-361 doi $10.1007 / \mathrm{bf00356279}$

R Core Team (2013) R: A language and environment for statistical computing. URL : http://www.R-project.org/, R Foundation for Statistical Computing, Vienna, Austria

Richards JG (2009) Chapter 10 : Metabolic and Molecular Responses of Fish to Hypoxia Fish Physiology, Vol 27 : Hypoxia. Academic Press, pp 443-485

Roze T, Christen F, Amerand A, Claireaux G (2013) Trade-off between thermal sensitivity, hypoxia tolerance and growth in fish. $\mathrm{J}$ therm biol 38:98-106

Semenza GL (2011) Hypoxia-inducible factor 1: Regulator of mitochondrial metabolism and mediator of ischemic preconditioning. BBA-Mol Cell Res 1813: 1263-1268 doi 10.1016/j.bbamcr.2010.08.006

Stierhoff KL, Targett TE, Miller K (2006) Ecophysiological responses of juvenile summer and winter flounder to hypoxia: experimental and modeling analyses of effects on estuarine nursery quality. Mar Ecol-Prog Ser 325: 255-266 doi 10.3354/meps325255

Thompson DB (1999) Genotype-environment interaction and the ontogeny of diet-induced phenotypic plasticity in size and shape of Melanoplus femurrubrum (Orthoptera : Acrididae). J Evol Biol 12: 38-48 doi 10.1046/j.1420-9101.1999.00005.x

Wexler JB, Margulies D, Scholey VP (2011) Temperature and dissolved oxygen requirements for survival of yellowfin tuna, Thunnus albacares, larvae. J Exp Mar Biol Ecol 404: 63-72 doi 10.1016/j.jembe.2011.05.002

Yamanaka H, Takahara T, Kohmatsu Y, Yuma M (2013) Body size and temperature dependence of routine metabolic rate and critical oxygen concentration in larvae and juveniles of the round crucian carp Carassius auratus grandoculis Temminck \& Schlegel 1846. J Appl Ichthyol 29: 891-895 doi 10.1111/jai.12126

Yang H, Cao ZD, Fu SJ (2013) The effects of diel-cycling hypoxia acclimation on the hypoxia tolerance, swimming capacity and growth performance of southern catfish (Silurus meridionalis). Comp Biochem Phys-A 165: 131-138 doi 10.1016/j.cbpa.2013.02.028

Zambonino-Infante JL, Cahu CL, Peres A, Quazuguel P, Le Gall MM (1996) Sea bass (Dicentrarchus labrax) larvae fed different Artemia rations: growth, pancreas enzymatic response and development of digestive functions. Aquaculture 139: 129138 doi 10.1016/0044-8486(95)01149-8

Zambonino-Infante JL, Claireaux G, Ernande B, Jolivet A, Quazuguel P, Severe A, Huelvan C, Mazurais D (2013) Hypoxia tolerance of common sole juveniles depends on dietary 
regime and temperature at the larval stage: evidence for environmental conditioning. Proc R Soc B 280: 9 doi 10.1098/rspb.2012.3022 
Table 1. Forward and Reverse Primer sequences used for quantitative PCR. * used as housekeeping gene.

\begin{tabular}{|c|c|c|c|}
\hline $\begin{array}{l}\text { Gene name } \\
\text { (abbreviations) }\end{array}$ & $\begin{array}{l}\text { Accession number on } \\
\text { ncbi (\$), unipd (\#) or } \\
\text { sigenae (\$) databasis }\end{array}$ & Forward primer sequence & Reverse primer sequence \\
\hline Elongation Factor 1 (ef1) * & AJ866727.1 (\$) & $5^{\prime}-$ GCTTCGAGGAAATCACCAAG-3' & $5^{\prime}-\mathrm{CAACCTTCCATCCCTTGAAC-3^{ \prime }}$ \\
\hline Glucose transporter 2 (glut2) & EF014277.p.dl.5 (\$) & $5^{\prime}$-CAGCTGATCGTTGCACTCAT-3' & $5^{\prime}-$ TGTGGCATAGACTGGCTGAG $-3^{\prime}$ \\
\hline Acetyl-CoA Carboxylase Alpha (acaca) & DLPD17871 (\#) & $5^{\prime}$-AGGCTCATGGGTGGTGATAG-3' & $5^{\prime}$-GTACCTTCAGCCTCCAGCAC-3' \\
\hline EGL Nine Homolog 3 (egln3) & DLPD06823 (\#) & $5^{\prime}-\mathrm{TCCTACTCCACCAGGTACGC-3^{ \prime }}$ & 5'-GCAGTCATGTTTGCTCTCCA-3' \\
\hline $\begin{array}{l}\text { Hypoxia inducible factor, isof. } 1 \text { alpha (hif- } \\
1 \alpha)\end{array}$ & DLPD10800 (\#) & $5^{\prime}-\mathrm{CCAAGAGAGGAGGCTTTGTG-3^{ \prime }}$ & $5^{\prime}$-GCCACTGAGCACAAAGTTGA-3' \\
\hline $\begin{array}{l}\text { Hypoxia inducible factor, isof. } 3 \text { alpha like } \\
\text { (hif-3a-like) }\end{array}$ & DLPD00697 (\#) & $5^{\prime}$-GACCTTCCTCAGCAGTTTCG-3' & $5^{\prime}-\mathrm{CTGAATCATCAGCTGGGACA}-3^{\prime}$ \\
\hline Lactate dehydrogenase, isof. a (Idh-a) & DV216873.p.dl.5 (\$) & $5^{\prime}$-GAAGCTCATCAGCCATGTGA-3' & $5^{\prime}-$ TCACACAGGTCCTTGAGCAG-3' \\
\hline Insulin-like Growth Factor (igf-1) & AJ579342.1 (\$) & 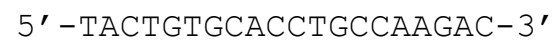 & $5^{\prime}$-CTGTGCTGTCCTACGCTCTG-3' \\
\hline
\end{tabular}


Table 2. Relative expression levels of genes involved in the HIF pathway, metabolism, growth and epigenetic regulation. Analysis was performed on RNA from whole European sea bass larvae exposed $(\mathrm{H})$ or not $(\mathrm{C})$ to hypoxia ( $\mathrm{n}$ for each group $=12$ pools of 3 larvae) and from hepatic and muscular tissues of juveniles from Early Life Hypoxia Treatment (ELHT) or Control (C) groups ( $\mathrm{n}$ for each group = 15 juveniles). P-value was calculated from an ANCOVA analysis. $N I=$ Not Investigated.

\begin{tabular}{|c|c|c|c|c|c|c|c|c|c|c|c|c|c|}
\hline \multirow{3}{*}{$\begin{array}{c}\text { Biol. } \\
\text { process }\end{array}$} & \multirow{3}{*}{ Genes } & \multicolumn{12}{|c|}{ Tissue and life stage } \\
\hline & & \multicolumn{4}{|c|}{ Whole larvae } & \multicolumn{4}{|c|}{ Liver of juvenile } & \multicolumn{4}{|c|}{ Skeletal muscle of juvenile } \\
\hline & & $\mathrm{C}$ & $\mathrm{H}$ & $\begin{array}{c}\text { p- } \\
\text { value }\end{array}$ & $\begin{array}{c}(\mathrm{H}-\mathrm{C}) / \mathrm{C} \\
(\%)\end{array}$ & C & ELHT & $\begin{array}{c}\text { p- } \\
\text { value }\end{array}$ & $\begin{array}{c}(\text { ELHT-C)/C } \\
(\%)\end{array}$ & C & ELHT & $\begin{array}{c}\mathrm{p}- \\
\text { value }\end{array}$ & $\begin{array}{c}\text { (ELHT-C)/C } \\
(\%)\end{array}$ \\
\hline \multirow[b]{2}{*}{ HIF pathway } & hif-1a & 0.82 & 0.83 & 0.779 & +1.2 & 1.15 & 1.09 & 0.509 & -5.6 & 1.08 & 1.05 & 0.504 & -2.8 \\
\hline & hif-3a-like & 0.73 & 0.80 & 0.052 & +9.6 & 0.99 & 0.98 & 0.689 & -1.2 & 1.06 & 1.10 & 0.684 & +3.8 \\
\hline \multirow{3}{*}{ Metabolism } & glut2 & 0.58 & 0.85 & $<10^{-5}$ & +46 & 1.15 & 1.01 & 0.032 & -12.3 & 0.81 & 0.97 & 0.58 & +19.7 \\
\hline & acaca & 1.00 & 0.89 & 0.001 & -11.0 & 0.90 & 0.69 & 0.025 & -23.3 & & & NI & \\
\hline & $I d h-a$ & 0.75 & 0.91 & 0.028 & +21.3 & 0.82 & 1.02 & 0.021 & +23.9 & 0.88 & 0.91 & 0.518 & +3.4 \\
\hline Growth & igf-1 & & & $N I$ & & 0.93 & 0.81 & 0.385 & -12.4 & 0.72 & 0.63 & 0.280 & -12.5 \\
\hline
\end{tabular}




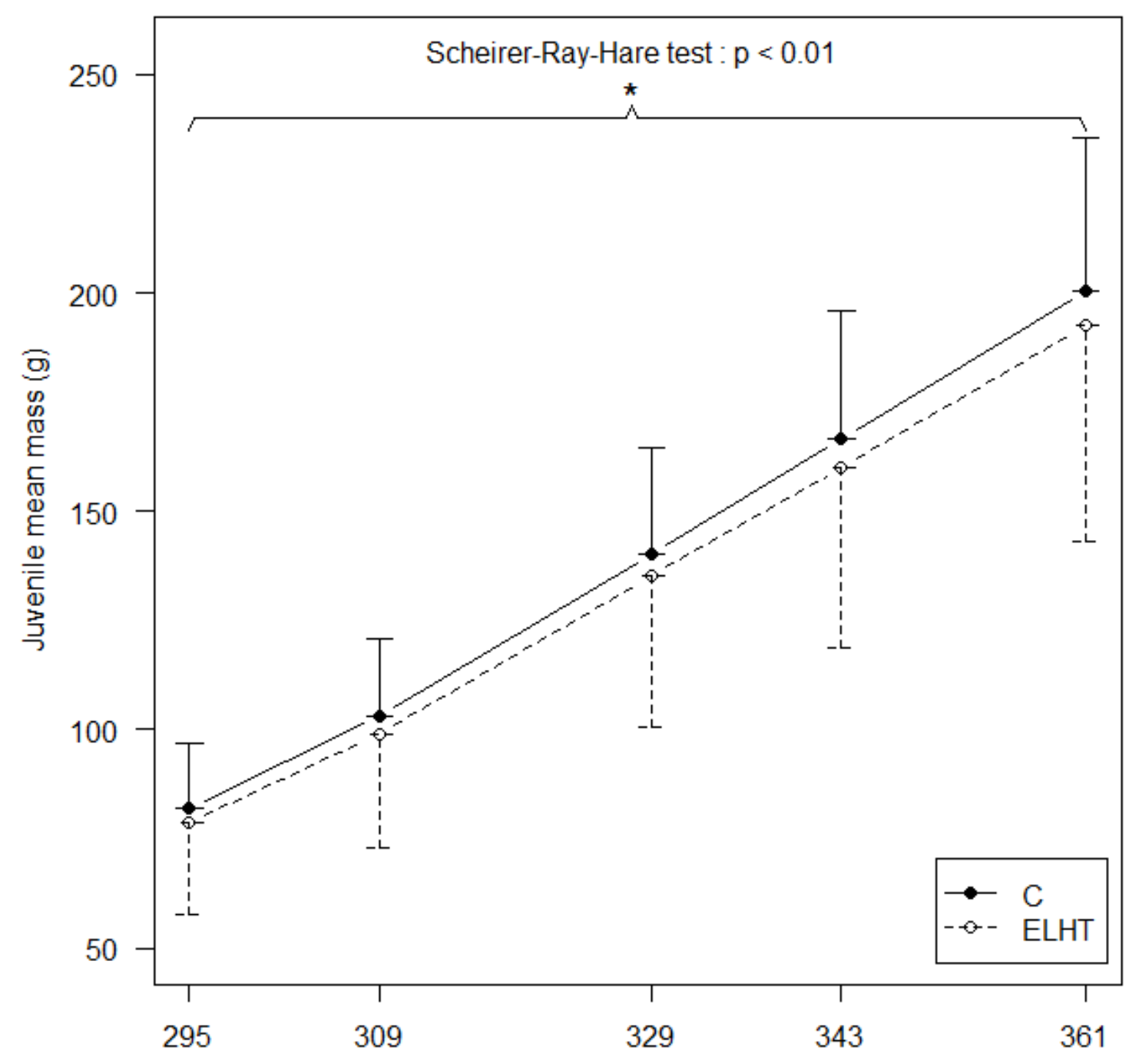

Age of juveniles in days post hatching

Figure 1: Mean mass of European sea bass juveniles previously exposed (ELHT :--) or not ( $\mathrm{C}:-)$ to a moderate hypoxia episode during larval development ( \pm s.d., $\mathrm{n}=40$ per group). Asterisk indicates significant differences in growth rate between the $\mathrm{C}$ and ELHT groups (Scheirer-Ray-Hare test: $\mathrm{p}<0.01$ ). 


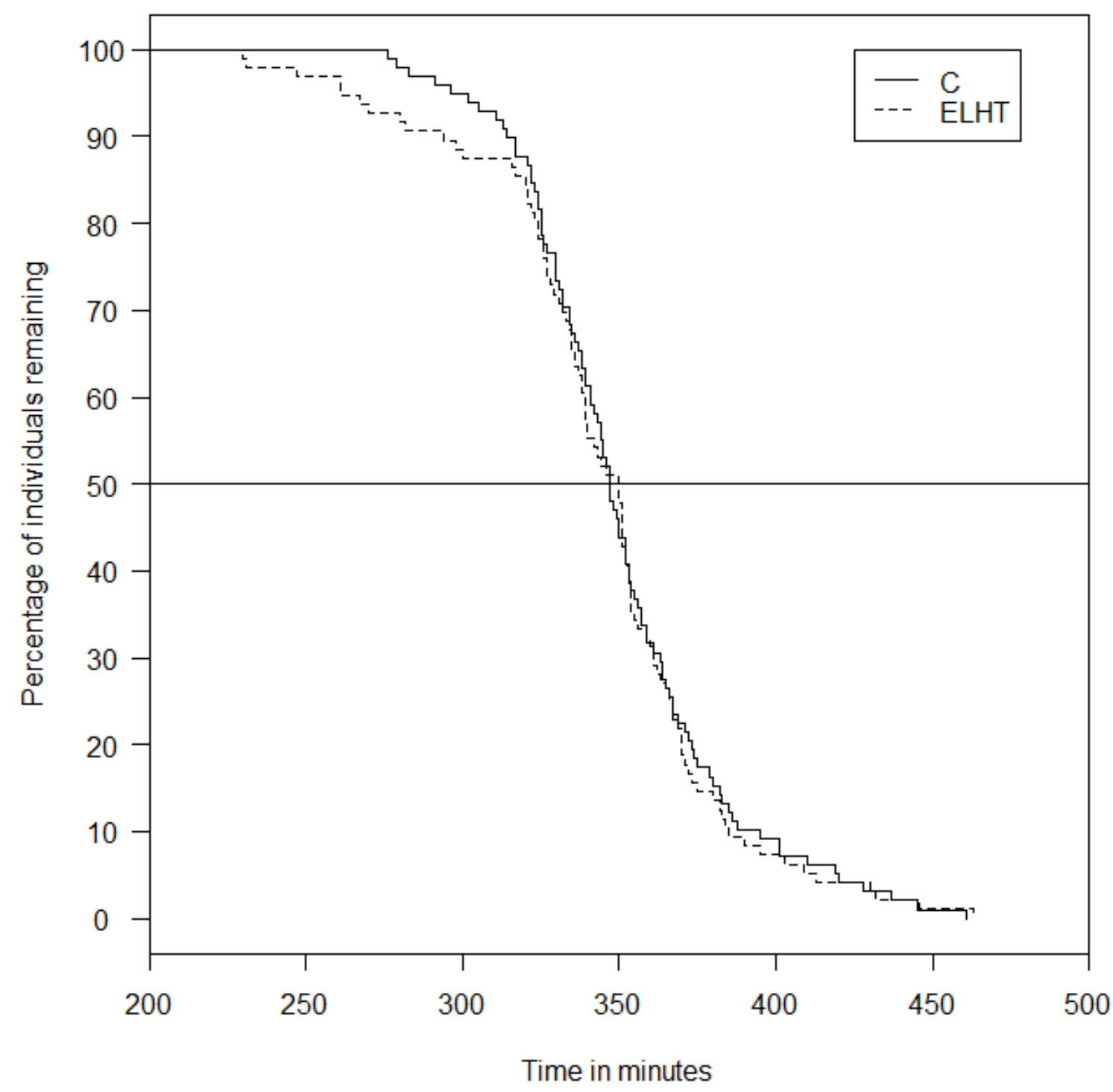

Figure 2: Kaplan-Meier probability plot of tolerance time during a Hypoxia Challenge Test in juveniles (253 d.p.h.) from Control (C :-) and Early Life Hypoxia Treatment (ELHT :--) groups ( $n=40$ per group). The horizontal line indicates time for removal of half of the population (T50). Statistical analysis showed that tolerance to hypoxia was not significantly different between the two groups (Mantel-Cox model: $\mathrm{p}>0.5$ ). 